\title{
Humble Opinion on Enhancing Occupational Values Education of Higher Vocational College Students
}

\author{
Xiangzheng Diao
}

School of International Education, Jiangsu Vocational Institute of Commerce, Nanjing 211168, China

Keywords: College students, Occupational values, Education.

\begin{abstract}
Occupational values affects the career orientation and choice of college students. The overall occupational values of students in higher vocational college is positive, while occupational values deviation problems still exist. Only when the enhancement of occupational values education of students of higher vocational college was combined with ideological and political education, occupational culture construction, occupational knowledge education, occupational experience activities and employment guide work etc. could a relatively good education effect be achieved.
\end{abstract}

\section{Introduction}

With the reform of college students' employment system and the fierce competition of employment competition, college students' employment problem has become the focus of the whole society, causing the concern from the whole society, while the employment pressure of higher vocational college students is bigger with employment problem more prominent. There are several factors leading to college students' employment difficulty, but among which there are problems in college students'occupational values. Occupational affects the professional attitude, career choice and career opportunity of college students. This is an important reason. In the process of career planning and development, occupational values plays a very important role of determining direction, therefore the employment guidance work of higher vocational colleges should take strengthening the occupational values education of college students as the main point. They should help higher vocational college students to get through their lost and confusion of profession, set up correct occupational motivations and occupational ideals and realize personal growth and career development.

\section{The current main problems of higher vocational college students' occupational values}

At present, the overall occupational values of higher vocational college students is positive, subject consciousness, competition consciousness, and develop consciousness of college students have been enhanced significantly. But at the same time, some students get too big-headed, being disconnected with social needs. They pay too much attention to the pursuit of material interests, being lack of rational judgment, thus causing many problems in their occupational valuess.

\section{The lopsided occupational understanding.}

As is known to all, fully understanding the occupational environment and effectively grasping the occupational information are the preconditions of setting up correct occupational values as well as elementary links for individuals to realize their career ideals. Surveys suggest that higher vocational college students take advantage of their professional practice opportunities to recognize social careers. But there are problems such as lopsided and subjective occupational understandings etc. in part of students. Some students know little about careers and jobs, just chasing hot jobs; Some students have fuzzy understanding of the match between personage and the occupation, subjectively thinking they are qualified for one job; Some students put too much emphasis on personal interests, not being able to go with the flow, thus not being able to establish their own career development path objectively and rationally, affecting their training of professional abilities.

Irrational occupational motivation.

College students are in a period physical and mental development not fully mature, self-awarenesses continuously strengthening, desire to be excellent constantly growing. They are 
eager to prove themselves through an ideal career, but easily be implied by others and have the herd behavior, or influenced by general mood of society and pursue utilitarian goals. Part of college students' career motivations have many irrational factors, they consider both meeting personal preferences and individual development and having good salary, besides considering factors such as occupation's degree of freedom, prestige-status etc. The orientation of their career goals contains obvious idealized part, this will generate contradictions between ideal and realistic when choosing a career and make them easy to be pessimistic, become an obstacle to the future employment and career development of college students.

\section{Blind and short-sighted career goal.}

Career goals refers to the specific goals a person will achieve in the selected professional fields in the future, it is the most direct reflection of the occupational values. Scientific career goal is a rational choice based on knowing yourself (self-cognition) and knowing your enemy(occupational understanding) as well as the basic premise of personal career success. At present, some higher vocational college students neither know themself nor understand the society, being lack of global, long-term considerations for the future. They are keen to grasp all practical professional skills, paying too much attention to personal interests, immediate interests and short-term returns instead of taking up an occupation in areas with relatively backward economic development and harsh living conditions. This blind, short-sighted tendency of choosing a career is easy to cause the desalination of the sense of social responsibility, going against college students' personal growth.

\section{Self centered professional conduct.}

The professional value orientation of college students in the new era has been developed from previous moral pursuit and behavior orientation of "obeying the overall situation, contributing to society, serving the country" gradually to focusing on individual ability and the realization of self-worth. ${ }^{[1]}$ Some students have obvious self-interest tendency, in the professional evaluation, they take individual needs and interests' meet as the evaluation standard and starting point, valuing the social status, power, money, etc. which are related to the interests of the individual; On the behavior of choosing a career, they prefer to choose the high-earning, comfortable and stable and promising career, ignoring the social responsibility and obligation, lack of spirit of utter devotion.

\section{Countermeasures to enhance higher vocational college students' occupational values education}

To strengthen the students' occupational values education in higher vocational colleges, it is necessary to constantly update the education concept, deepen the education reform and build a comprehensive system of occupational values education, inflicting all-round, multi-level influence on college students to cultivate to make the occupational values education deeply rooted in the hearts of the people and won solid results.

The combination of occupational values education and ideological and political education.

The content of ideological and political education includes the occupational values education content, the effect of ideological and political education of university students directly influences the establishment of university students' occupational valuess. Therefore, the ideological and political education of college students should fully consider the characteristics of vocational education and training requirements, targetedly strengthen the occupational values education to make college students improve the ideological and political awareness at the same time understand and know in-depth the professional environment, professional morality and social development needs so as to set up the correct idea of choosing a career as well as becoming elite athlete.

Ideological and political education should take solving the problem of college students' thought as the key point to promote the professional consciousness, mainly includes: to promote the liberation of the college students' self consciousness, training the initiativity, creativity and independent consciousness of work; to inspire students to pursue ambitious career ideal, down-to-earth, hardworking, promote their personal growth; to strengthen the sense of responsibility and dedication of college students, make them take the initiative to join in the construction of socialism with Chinese characteristics and realize the value of life. Ideological and political education should put forth efforts to solve the practical problems of college students. It should combine the employment demand and 
development desire of college students in higher vocational colleges, strengthening their education on national, social and community conditions to let students understand the employment policy, employment situation and society, enterprise's demand for talent, promoting their thinking and exploration of self career path, guiding them to obey the basic professional codes of conduct such as honest and trustworthy, cherishing posts and devoting wholeheartedly to work, obeying the overall situation and teamwork etc. to become a qualified professional person. ${ }^{[2]}$

The combination of occupational values education and professional culture construction.

The goal of occupational values education is not only to help college students to establish a scientific career attitude and plan their careers by strengthening college students' career cognitive, but more to focus on cultivation of the personality, moral sentiment and the sense of responsibility, professional spirit of college students etc. to make the student become a person with belief, pursuit and ability. Culture is an important means of education. Culture can convert education with characteristics of infuse into an environment which contains the education purpose, subtly affecting people. Therefore, professional culture is both an important means and an effective carrier of college students' occupational valuess education.

High vocational education has the dual nature of higher education characteristic and professional characteristic. Professional culture should become an important part of high vocational campus culture. Professional culture construction should focus on the infiltration of corporate culture, conduct a series of education activities around professional norms, professional ethics and professional quality, etc., creating an educational environment with obvious professional characteristics, teaching through lively activities, cultivating occupational values of college students. Specifically, the professional culture construction includes the construction of material culture, spiritual culture and institutional culture. Construction of teaching requires teachers to strengthen links with the industry, enterprise and improve the competency of theory with practice, have scientific education idea, good moral accomplishment and superb business skills. System culture mainly have the effect of specification. Higher vocational colleges can innovate students' education management discipline with reference to industry requirements and enterprise management standards, guaranting college students' good professional behavior and professional moral level.

The combination of occupational valuess education and professional knowledge education.

Professional knowledge education is an education activity to help students acquire professional theoretical knowledge and practical skills, training professional talents for related professions. Because the professional education curriculum reflects the contemporary science and technology level as well as also people's value judgments and value choice for the requirements of professional quality, professional education itself contains the value of educating people, mining the occupational values in professional teaching can make the high vocational students become double beneficial owners of knowledge skills and value education. ${ }^{[3]}$ Teachers can use abundant professional, occupational information and the background of the industry, enterprise to stimulate students's concern for occupation, strengthen their pursuit of inner value, expand their professional quality.

The occupational values education points out the direction for professional knowledge education, professional knowledge education provides a platform for the occupational values education. On the one hand, professional knowledge education is dependent on the lead of values. In the process of professional knowledge education, it should manifest the humanities concern, that is, not only pay attention to students' vocational skills training, more to strengthen college students' mental education and morality education, to cultivate people with all-round development. At present, higher vocational colleges should take the socialist core values as the guidance, combining the characteristics of different professions, concising distinctive professional values to expand the professional qualities and the humanities of students. On the other hand, occupational values education should be integrated with professional knowledge education together. It should perfect the system of putting professional quality into teaching evaluation system of specialized courses, improve the teaching system of which occupational values education permeated into professional courses. ${ }^{[4]}$ This requires teachers to pay attention to developing and mining the professional culture connotation, guiding the students to percept, experience and internalize the professional spirit, professional belief and professional norms 
to make the occupational values education more specific and situated, explicit so that be easy to be identified and acceptedby the college students.

The combination of occupational valuess education and professional experience activities.

Higher vocational colleges is mainly focusing on training of application-oriented high-skilled talents adapted to the social needs. In addition to the education of students' basic quality, the more important is to foster student's future career field ability, pioneering ability and ability to adapt. Therefore, work-learning integrated, practice teaching have become the focus of the teaching and education work in higher vocational colleges. Professional experience activities breakthrough the limitations of traditional teaching of theoretical knowledge infusion, attaching great importance to the theory with practice and participation of student's main body, enhancing the education teaching effectiveness greatly. There are three main professional experience activities for higher vocational colleges to carry out, the first is the social practice. It makes the students know more about their own interests and specialties, learning more about the needs of society by organizing students to participate in social research and social service activities. It cultivates the students' comprehensive ability. The second is professional training. By using professional training base, it lets the students carry on simulation exercises, percept job content, cultivate professional emotion, temper their career will; The third is post practice. It lets the students have real experience of professional life in the real business scenario and feel the enterprise culture and develop professional quality through the university-enterprise cooperation.

The occupational valuess can only be formed through a series of professional experience activities so as to achieve the gradual unification of "cognition, emotion, meaning, action", ultimately becoming stable career values. ${ }^{[5]}$ College students' bad behavior habits can be corrected through the constraints of professional norms, principles of moral timely, at the same time, students' correct occupational valuess, firm professional determinations and rational professional behaviors can more be trained and culticated, thus transition of college students from "campus people" into "professional people" can be achieved.

\section{Combination of occupational valuess education and employment guidance work.}

Employment guidance work is an important link of the system of higher vocational education which can not only give students timely professional information, teach students practical job skills, but also cultivate students healthy employment psychology, strong career planning consciousness and good professional quality. Employment guidance work is the main land to cultivate college students' occupational valuess. First of all, it will guide students in career planning. Started from entrance education of freshmen, it will guide students to have objective self-understanding and understanding of the society, gradually clear their personal career ideal, formulate a reasonable plan of study and career goals to help students to avoid confusion in study and choosing a career blindly in future to promote their growth. Second, paying attention to students' employment guidance demand. College employment guidance departments should elaborately organize job fairs, workplace simulation training, employment entrepreneurship competition and field work activities, etc. to build a platform of experiencing professional role and promoting comprehensive ability of employment for the students. For graduates, it will help them to collect employment information, analyze employment situation, teach them job skills and guide them to correct their employment goals. Finally, it will strengthen students' employment psychological guidance. It will guide students to find their own professional personality, personality psychological characteristics such as vocational interest and vocational ability, comprehensively and objectively understand themself through the theoretical knowledge explaination, typical case analysis, scientific assessment and psychological counseling. In addition, in view of part of the students' high employment expectations, not strong psychological ability, lack of subjective initiatives, the schools should strengthen employment psychological counseling to help them adjust the mentality, strengthen the consciousness of free-standing self-improvement, help them to change roles as soon as possible to adapt the society.

Anyhow, higher vocational colleges should explore the ways and methods to strengthen college students' occupational valuess education and promote the students to change ideas, help them plan their careers reasonablely based on personal development and social needs, enhance their ability of 
career choice and development so as to make them succeed in the fierce employment competition as well as achieve career goals and life value.

\section{Acknowledgments}

This article is the phased achievement of Philosophy Social Science Research Fund Project of Colleges and Universities in Jiangsu Province, serial number: 2014SJD266.

\section{References}

[1] Zhang Jiyan. College students' occupational valuess education path, Journal of ideological education research, 2010, (9):48.

[2] Zhang Xiangyun Yin Jin Tong. Thinking on dislocation of supply and demand of occupational valuess education in higher vocational education, Vocational \& Technical Education Forum, 2009, (4) : 23.

[3] Ma Jing. Exploring new occupational valuess development path of higher vocational college students, China's adult education, 2011, (21) : 94.

[4] Ge Jun Yan. Occupational valuess education: the target, characteristics and its path - exploring based on vocational college students' vocational life experience, Journal of China higher education research, 2012, (9) : 105.

[5] Xue-zhong Chen. Agriculture vocational values cultivation and study of students major at agricultural and economic and trade in higher vocational colleges, Journal of vocational and technical education in China, 2014, (12) : 57. 